\title{
Objective
}

A poor vitamin $\mathrm{D}$ status has been related to an increased risk of cardiovascular disease Carotid intima media thickness has shown to be an early marker of subclinical atherosclerotic Our aim was to assess the relationship between hypovitaminosis D and intimal medialthickening (IMT) of the common carotid artery as a marker of preclinical atherosclerosis

\section{Material and Metbod}

In a Cross sectional study 78 Type 2 diabetic patients attending the Diabetes and Endocrinology clinic in Kasr El Ani hospital

All patients were subjected to:Full medical history Complete physical examination.BMI, waist circumference tfasting glucose,HOMAIR , serum cholesterol ,triglycerides, LDL,HDL 25(OH) vitamin D measurement , carotid doppler to measure intima media thickness of the distal common carotid

\section{Results}

Diabetics with normal CIMT $(n=26)$ all with sufficient Vit D, Diabetic with increased CIMT $n=52$ (40 sufficient $76.9 \%, 12$ insufficient $23.1 \%$ )

6 Patients with increased CIMT had carotid plaque Only one patient had vit D insufficiency, all 5 patients had sufficient vit $D$ Vit $D$ negatively correlated with Rt intimal media thickness however not statistically significant $(r=-0.003, p=0.981)$

Negative correlation between fasting blood glucose and vit $D$ statistically significant $(r=-0.415, p<0.001)$.Negative correlation between cholesterol and Rt intima $(r=-0.340, p=0.002)$

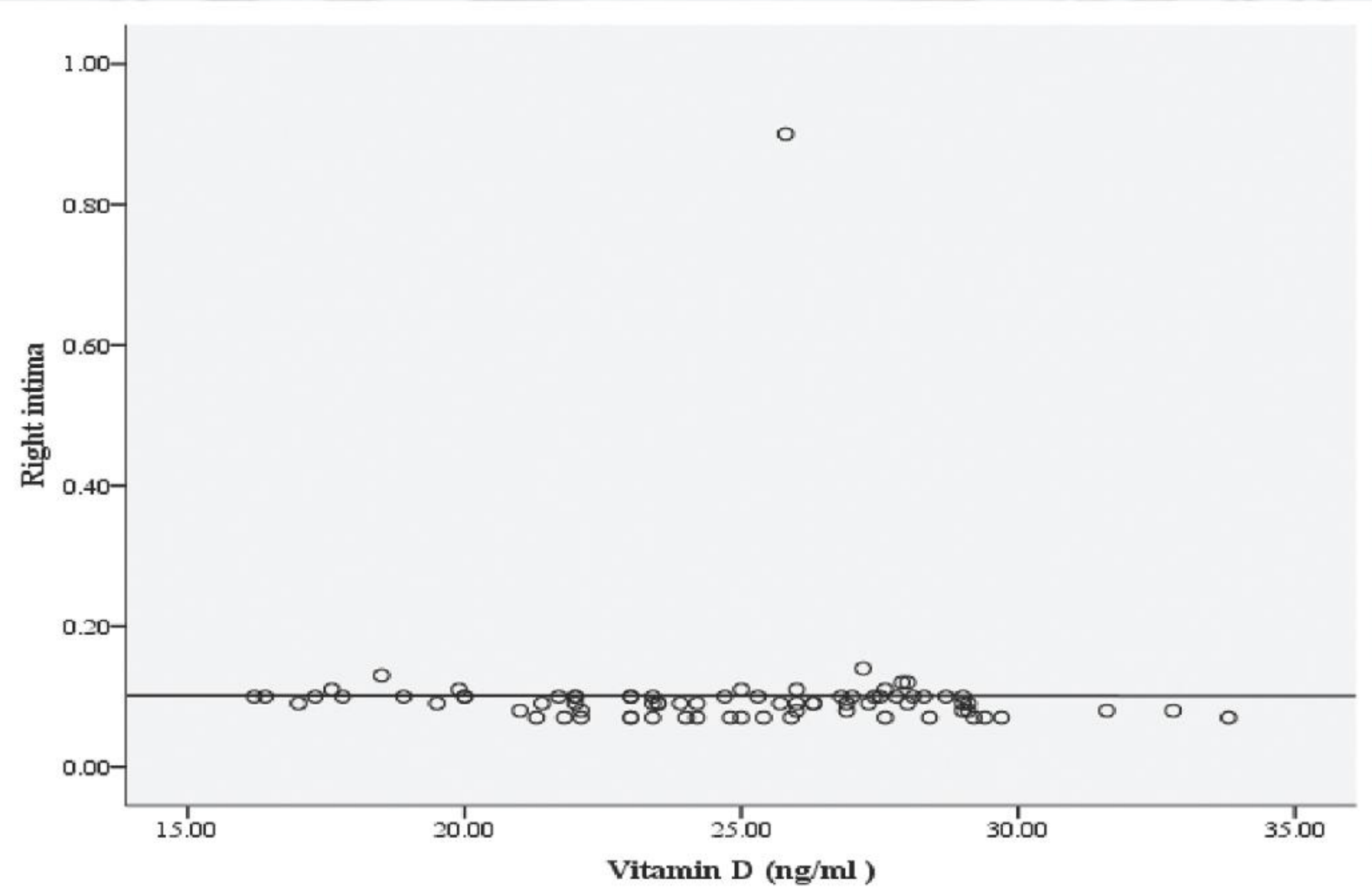

\begin{tabular}{|c|c|c|c|c|c|}
\hline & \multicolumn{4}{|c|}{ Vitamin D status } & \multirow{3}{*}{ Pvalue } \\
\hline & \multicolumn{2}{|c|}{ Insufficiency } & \multicolumn{2}{|c|}{ Sufficiency } & \\
\hline & Mean & $\begin{array}{l}\text { Standard } \\
\text { Deviation }\end{array}$ & Mean & $\begin{array}{l}\text { Standard } \\
\text { Deviation }\end{array}$ & \\
\hline age & 51.00 & 9.20 & 48.55 & 8.36 & 0.360 \\
\hline diabets & 8.50 & 1.83 & 7.18 & 3.45 & 0.203 \\
\hline Systolic BP & 139.17 & 13.79 & 133.94 & 16.81 & 0.313 \\
\hline Diastolic BP & 89 & 8 & 88 & 12 & 0.587 \\
\hline weight & 84.00 & 14.93 & 84.21 & 12.55 & 0.958 \\
\hline$B M I$ & 33.83 & 5.47 & 33.05 & 5.09 & 0.627 \\
\hline $\begin{array}{l}\text { Vitamin D } \\
(\mathrm{ng} / \mathrm{ml})\end{array}$ & 18.26 & 1.40 & 25.91 & 2.90 & $<0.001$ \\
\hline$F B G$ & 195.50 & 47.06 & 180.02 & 46.88 & 0.296 \\
\hline HOMA & 4.86 & 1.11 & 6.24 & 2.81 & 0.005 \\
\hline Cholestrol & 190.67 & 32.09 & 199.91 & 36.82 & 0.418 \\
\hline$T G$ & 94.08 & 45.59 & 108.65 & 55.05 & 0.391 \\
\hline$H D L$ & 41.58 & 7.48 & 40.24 & 8.51 & 0.611 \\
\hline$L D L$ & 136.58 & 25.20 & 133.24 & 34.19 & 0.748 \\
\hline
\end{tabular}

\section{Conclusion}

Low serum 25(OH)D has no consistent association with mean IMT. Thus could not predict subclinical atherosclerosis in diabetics, the contribution of the local activated vitamin D system within atherosclerotic plaque has not been appropriately investigated yet. Therefore, both basic research studies and clinical trials are needed for better elucidating the therapeutic and path physiological role of vitamin $D$ in atherogenesis and CV diseases.

\section{Reference}

1- Kamycheva E, Johnsen SH, Wilsgaard T, et al. : Evaluation of Serum 25-Hydroxyvitamin D as a Predictor of Carotid Intima-Media Thickness and Carotid Total Plaque Area in Nonsmokers: The Tromsø Study. International Journal of Endocrinology Volume 2013 2-Melamed ML, Muntner P, Michos ED, Uribarri J, Weber C, Sharma J, et al. Serum 25-hydroxyvitamin D levels and the prevalence of peripheral arterial disease: results from NHANES 2001 to 2004. ArteriosclerThromb Vasc Biol 2008;28:1179e85

\section{key words}

Diabetes , atheroselerosis , carotid media 